\title{
Women Empowerment and Fertility Management in Nigeria: A Study of Lafia Area of Nasarawa State
}

\author{
Stephen S. Ojo \\ Ayesoro Sunday Adesina
}

Department of Social Development, Nasarawa State Polytechnic, P.M.B 109, Lafia-Nigeria

\section{Doi:10.5901/mjss.2014.v5n26p9}

\begin{abstract}
Women's empowerment is vital to sustainable development and the realization of human rights for all. Where women's status is low, family size tends to be large, which makes it more difficult for families to thrive. The ability of women to control their own fertility is absolutely fundamental to women's empowerment and equality. Hence, this study explores the relationship between women empowerment and their capacity to manage their fertility assuming other factors are held constant. Two hundred women of working age and married were selected in the study area. The selection of the 200 respondents was done using the stratified random sampling technique, to ensure the representativeness of the sample. One hundred and eighty-four (184) copies of the unstructured questionnaire out of the two hundred sent out were returned and treated for the analysis. The coefficient contingency distribution and the chi-square (X2) techniques were employed. The findings show that the level of women's education, women's employment status and women's level of income, influences them to adopt small family size. The study concludes that fertility management is a very potent tool for women empowerment and vice versa. With advancement towards gender equity and equality and as women's opportunities for self-actualization expands, their options increase, women will progressively more seek ways of managing their fertility.
\end{abstract}

Keywords: women, empowerment, fertility, management, development

\section{Introduction}

Until the last decade and a half, the gains of women from development were minimal and temporal while the entire process intensified gender inequalities even in periods of national prosperity. Although the United Nations Development Decades for women raised awareness about the strategic and practical needs of women, there was little commitment to incorporate these into national and sectorial policies until the mid-1990s when there developed the yearning for a national women's development policy to facilitate the full integration of the women into the social, economic and political sectors of the nation.

A critical aspect of promoting gender equality is the empowerment of women, with a focus on identifying and redressing power imbalances and giving women autonomy to manage their own lives. Women's empowerment is vital to sustainable development and the realization of human rights for all. Where women's status is low, family size, tends to be large, which makes it more difficult for families to thrive. When women are empowered, the whole families' benefits and these benefits often have ripple effects to future generations (United Nations, 2011).

The ability of women to control their own fertility is absolutely fundamental to women's empowerment and equality. When a woman can plan her family, she can plan the rest of her life. When she is healthy, she can be more productive. And when her reproductive rights including the right to decide the number, timing and spacing of her children and to make decisions regarding reproduction free of discrimination, coercion and violence are promoted and protected, she has freedom to participate more fully and equally in society.

The study of fertility is very important in the field of social sciences, for fertility determines the rate of population growth in a country. In developing countries, like Nigeria, where there is a high fertility level, the issue of managing fertility is of central concern. Within the limit of established physiological factors, a multiplicity of economic, social and cultural factors are the ultimate determinants of fertility levels and their variation in different societies (Isuigo-Abanihe, 1996). Fertility is the actual level of reproductive performance in the population with respect to children ever born. Therefore, reduction in fertility is necessary to bring about a solution to the sufferings of the people. It reduces cost of living, improves means of survival and redeems self-esteem. Similarly, it improves the nation's economic growth and development. 
Hence, this study is to explore the relationship between women empowerment and their capacity to manage their fertility assuming other factors are held constant.

\subsection{Statement of the problem}

It has been said that "women hold up half the sky." Around the world, women play a vital role in providing for families, sustaining communities and managing natural resources. Yet too many lack the means to improve lives and shape the planet's future. When women are economically and socially empowered, they become a potent force for change. In rural areas of the developing world, women play a key role in running households and make major contributions to agricultural production. But the inequalities that exist between women and men make it difficult for women to fulfil their potential (Unfpa, 2006)

Despite many international agreements affirming their human rights, women are still much more likely than men to be poor and illiterate. They usually have less access than men to medical care, property ownership, credit, training and employment. They are far less likely than men to be politically active and far more likely to be victims of domestic violence.

These questions will guide the study:

i. What is the nature of women empowerment?

ii. Is fertility a constraint on women empowerment? And if so, when? And to what extent?

iii. Does women empowerment depress their fertility?

iv. What are the measures of relationship, if any?

\subsection{Objectives of the study}

The general aim of this study is to contribute to the general knowledge on the study of fertility management from women empowerment point of view. However, it attempts to focus specifically on the following:

i. To investigate the effect of women employment status on fertility preferences

ii. To observe the influence of education attainment of women on their fertility preferences

iii. To analyse the influence of women level of income on fertility preferences

\subsection{Hypothesis of the research}

The study proposes the following hypothesis to be tested:

i. The higher the level of women's education, the greater their preferences to adopt small family size

ii. Women's employment status will likely influence their preference to adopt small family size

iii. There exist a relationship between the women's level of income and their preference to adopt small family size.

\subsection{Significance of the study}

Empowering women through better education, economic opportunity and health care, including family planning is pivotal to world progress, with far-reaching benefits for families, communities and the planet. Women rarely have access to the resources that would make their work more productive and ease their heavy workload. Ultimately, it is not just women who are held back, but also their families, their communities and local economies.

The study will create awareness for the importance of empowering women in order to control fertility and also increase knowledge in addressing the multidimensional problems being faced by women in the study area.

\section{Review of Related Literature and Conceptual Framework}

Empowerment is the process in which women challenge the existing norms and culture to effectively improve their wellbeing. Mayoux (2005) defines empowerment as a multidimensional and interlinked process of change in power relations. Also women's empowerment is seen as the process through which women achieve gender equality (and equity). DFID (2005) describes women's empowerment as a process of transforming gender relations through groups or individuals developing awareness of women's subordination and building their capacity to challenge it. According to Krishna (2003) empowerment is the process of increasing the capacity of women to make choices and to transform these choices into 
desired actions and outcomes. Also Kabeer (2001) sees it as the expansion in women's ability to make strategic life choices in a context where this ability was previously denied to them.

Women not only face various gaps as females, but they may also belong to another disadvantaged category. Their lack of empowerment often originates within the household or family and their empowerment needs a major transformation, especially in patriarchal societies (Malhotra and Mark, 1997). The term fertility management is the skills used in handling individual's understanding of male and female reproductive anatomy and physiology as it relates to fertility. For a woman it includes being able to control or identify the fertile time during her menstrual cycle. For a man it includes understanding his own reproductive potential. For a couple it includes developing a shared understanding about their fertility potential at different stages of their lives and their ability to communicate about fertility issues with each other and with health professionals. Knowledge about fertility management is fundamental to making informed decisions about reproductive and sexual health (United Nations, 2012).

In spite of the considerable attention devoted to the investigation of the relationship between women's employment and fertility in the demographic literature, the empirical studies, however, have not been able to come up with a precise and consistent explanation of the relationship between the two variables in developing countries. Unlike in developed countries, especially the United States, where empirical studies consistently find negative effects of employment on fertility, finding for Africa, are missing. The results vary from a negative relationship (Lewis 1998, Simon 1999) to positive (Arowolo 1998, Ahmed 1999) and even to no relationship between employment and fertility (Uyanda 1996; Dalencey 1999). One common trend running through those conflicting studies is the neglect of factors such as family structure and women's social position within the household or society with little or no realization that such factors may influence a woman's decision about fertility.

Lloyd (1991) conducted a World fertility survey (WFS) but contributed little information about the association between women's work and fertility. But this limited information is not inconsequential. First, the world fertility survey (WFS) confirmed that the association between women's work and fertility differs greatly between and within developing countries. The survey also revealed that some aspects of social conditions, for instance, level of socio-economic development, only explain part of the differences in the relationship between developing countries.

Oladimeji (1999) focuses on a social structure analysis of women's employment and fertility in Nigeria, by looking at how the structure of the family, ethnicity and women's position within the household or society impact on their fertility management. The data came from a 1998 national survey of 8259 currently married women in urban Nigeria and multinational logistic regression models were used to estimate employment effect at specific parities during a 5-year period. The findings, indicate that, Nigerian women employed in either the formal or informal sector are more likely to control their fertility than, those not working; since they have had one birth or at least two births within a 5-year period, after controlling for socio-demographic and family characteristics.

Following demographic theories that scare people about the damages of over population, organizations, groups and agencies have been trying to reduce fertility especially in the developing nations, considered as poor. Western ideologies have been brought in to explain why a woman needs fewer children. For example, Africans have a culture that values children not only as economic factors of production but as individuals valued for their own inherent value. It is difficult for Africans to think of children in terms of the western concept as commodities whose value is determined by market forces. While western culture hinges on individualism, African culture hinges on community values, the kin, the extended family, the environment around us.

The theory of demographic transition helps in the assessment of whether the United Nations projections will actually occur. Under Notestein's model, economic and social gains such as rising income and educational levels encourage the birth rate to fall, which in turn leads to further economic and social gains because families with fewer children devote fewer resources to raising their children, freeing those resources for other purposes, such as savings and investment.

\section{Methodology}

\subsection{Location of the study}

Lafia is the capital city of Nasarawa State in North-Central Nigeria as well as being a local Government Area headquarters. It is bounded on the west by Doma Local Government area, on the south by Obi Local Government area, on the north by Nasarawa Eggon Local Government area and on the east by Quan-Pan LGA of Plateau State, Nigeria. People from virtually all parts of the country live in the city; the ethnic groups Eggon, Kanuri, Migili, Alago, Tiv, e.t.c. According to the 2006 census, the population was 330,712 . Not only is Lafia a market town for the surrounding area, it is 
the home of numerous artisans from traditional crafts like leather work, dyeing and cap making to tinkers, print shops and furniture makers. Lafia's economy is primarily base on agriculture, staples are guinea corn, and millet and cash crops include groundnuts

Two hundred women of working age married were selected in the study area. The selection of the 200 respondents was done using the stratified random sampling technique, to ensure the representativeness of the sample, and this covered the wards that constitute the study area. One hundred and eighty-four (184) copies of the questionnaire out of the two hundred sent out were returned and treated for the analysis. The co-efficient contingency and the chisquare $\left(X^{2}\right)$ techniques were employed.

\section{Presentation and Analysis of Data}

To show in more lucid manner, the relationship between formal education and fertility preferences of working women, our hypothesis is subject to testing using Chi-square technique and co-efficient contingency.

The null ( $\mathrm{HO}$ ) hypothesis is that there exist no significant relationship between the level of women's education and their preferences to adopt small family. The alternative (H1) hypothesis is that the higher the level of women's education, the greater their preference to adopt small family size.

Table 1: Fertility preference and Educational level of the Respondents

\begin{tabular}{|c|c|c|c|c|c|}
\hline No of preferred Children & $\begin{array}{c}\text { Education } \\
\text { None }\end{array}$ & $\begin{array}{c}\text { Education } \\
\text { Primary }\end{array}$ & $\begin{array}{c}\text { Education } \\
\text { Secondary }\end{array}$ & $\begin{array}{c}\text { Education } \\
\text { Tertiary }\end{array}$ & Total \\
\hline $0-2$ & $1(1.98)$ & $1(1.98)$ & $7(8.22)$ & $19(15.83)$ & 28 \\
\hline $3-4$ & $1(6.15)$ & $4(6.15)$ & $22(25.53)$ & $60(49.17)$ & 87 \\
\hline $5-6$ & $3(2.76)$ & $2(2.76)$ & $17(11.45)$ & $17(22.04)$ & 39 \\
\hline 7 and above & $7(1.34)$ & $6(1.34)$ & $5(5.58)$ & $1(10.74)$ & 19 \\
\hline Indeterminate & $1(0.78)$ & $0(0.78)$ & $3(3.23)$ & $7(6.22)$ & 11 \\
\hline Total & 13 & 13 & 54 & 104 & 184 \\
\hline
\end{tabular}

Source: Field survey, June, 2013

Calculated chi-square----------63.759 Critical value-------21.030

Alpha level---------------0.05, Degree of freedom------12

Using 0.05 level of significance, the result, as shown in table 1 , is that Chi-square computed $\left(X^{2}\right)$ value $(63.759)$ is greater than the chi-square tabulated value (21.030). We can, therefore, reject the null hypothesis (H0) and accept the alternative hypothesis ( $\mathrm{H} 1)$. This implies that the higher the level of women's education, the greater their preference to adopt small family size. This is confirmed from the co-efficient of contingency, which shows 85 percent degree of relationship or association.

Hypothesis II: size.

H0: There exist no relationship between women's employment status and their preference to adopt small family

H1: There exist relationship between women's employment status and their preference to adopt small family size.

Table 2: Fertility preference and Employment status of the Respondents

\begin{tabular}{|c|c|c|c|c|}
\hline No of preferred Children & $\begin{array}{c}\text { Employment status: } \\
\text { Self-employed }\end{array}$ & $\begin{array}{c}\text { Employment status: } \\
\text { Govt-employed }\end{array}$ & $\begin{array}{c}\text { Employment status: } \\
\text { Private -employed }\end{array}$ & Total \\
\hline $0-2$ & $7(6.783)$ & $7(5.82)$ & $2(3.39)$ & 16 \\
\hline $3-4$ & $25(37.30)$ & $35(32.04)$ & $28(18.65)$ & 88 \\
\hline $5-6$ & $22(21.19)$ & $20(18.20)$ & $8(10.60)$ & 50 \\
\hline 7 and above & $15(7.20)$ & $1(6.19)$ & $1(3.60)$ & 17 \\
\hline Indeterminate & $9(5.51)$ & $4(4.73)$ & $0(2.75)$ & 13 \\
\hline Total & 78 & 67 & 39 & 184 \\
\hline
\end{tabular}

Source: Field survey, June, 2013 
Calculated chi-square---------28.84 Critical values------16.51

Alpha level-----------------0.05, Degree of freedom------8

This conclusion is further examined using the chi-square $\left(X^{2}\right)$ technique to test the hypothesis of existence of association between fertility preference and employment status of working women. The null ( $\mathrm{HO})$ hypothesis is that there exist no relationship between women's employment status and their preference to adopt small family size.

As shown in table above, the chi-square computed $\left(\mathrm{X}^{2}\right)$ value is 28.84 while the chi-square table value is 16.51 at 0.05 level of significance. The alternative hypothesis $(\mathrm{H} 1)$ is therefore accepted, with a conclusion that the women's employment status influences them to adopt small family size. But the degree of association is only significant up to 36.4 percent level when the contingency coefficients were computed.

HYPOTHESIS III

HO: There exist no relationship between women's level of income and their preference to adopt small family size. H1: There exist relationship between women's level and their preference to adopt small family size.

Table 3: Women's level of income and fertility preferences

\begin{tabular}{|c|c|c|c|}
\hline Responses & Women empowerment & Fertility preferences & Total \\
\hline Agreed & $111(105.6)$ & $16(21.39)$ & 127 \\
\hline Disagreed & $42(55.71)$ & $15(11.29)$ & 67 \\
\hline Total & 153 & 31 & 184 \\
\hline
\end{tabular}

Source: Field survey, June, 2013

Calculated chi-square----------------6.23 Critical value-------------------------3.84

Alpha level----------------------0.05 D.f----------------------------1

The calculated chi-square is more than the table chi-square. Therefore there is a significant relationship between women's level of income and their fertility preferences. The alternative hypothsis (H1) is therefore accpeted.

\section{Conclusion}

The population growth is at an alarming rate; the economy is not affecting the standard of living of the majority of the population. The need to curb the unprecedented population rate is inevitable. Understanding the social structure and the empowerment of women will enhance her social status thereby enabling them to take decisions as regards their fertility rate. It was also observed in this study that women's education is the most important variable that affects fertility preferences, not only by enabling women to engage in activities outside the home, but also by delaying age at marriage, by introducing a conscious and well-thought decision regarding the number of children they desire to have and by making proper allocation of the available time between activities within and outside the home, generating employment opportunities for women in the formal sector.

Similarly, the study confirmed that there exist a positive relationship between the women's level of income and their preference to adopt small family size. Thus, there is compelling evidence to conclude that women's level of income have a central role to play in determining fertility management among women. When women are empowered through education, capacity enhancement, more skills, high income, more opportunities and options in the superstructure they will voluntarily lower their fertility.

The control factors in this demographic transition are the women. What societies do to empower their women and what they do not do is going to determine the population structure. Whatever population structure a nation desires will be determined by the quality of its women folk. Given the foregoing discourse, a lot of responsibility is placed on women to determine the socio-economic future of their societies as bearers of prosperity.

Fertility management is a very potent tool for women empowerment and vice versa. With advancement towards gender equity and equality; as women's opportunities for self-actualization expands, their options increase, women will increasingly seek ways of managing their fertility.

\section{Recommendations}

Female education is one of the ways of increasing the age of marriage and thereby, reduces fertility. When females are well-educated, they will not only serve the purpose of bearing and bringing up children alone, but also know their rights 
and have definite plans for their lives. Women should be encouraged to participate more in the labour force by providing employment opportunities for them. The education of women and their employment also gives the women prestige and this helps to reduce the importance attached to giving birth to many children.

Non Governmental Organisations (NGOs) and other women society should through extension work teach urban and rural women better ways of improving their income and also impact adequate knowledge on family planning majors, so that they will have few numbers of children which they will be able to cater for. In addition, programs should focus to keep girls in schools and prepare them for economic and independence, even within the marriage, vocational training should be impacted to them so that they learn to earn something that matters. The Government should promote global justice by challenging people, religious groups and others to share their resources through socially responsible investments and by empowering disadvantaged people with credit particularly the women.

\section{References}

Ahmed, F.A. (1999). Women's education, employment and fertility in Egypt. Cairo Demographic Centre219-42

Arowolo, O.O. (1998). Fertility of urban Yoruba working women.A case study of Ibadan city. The Nigeria Journal of Economic and Social studies.19(1) 37-66.

Delancey, V. (1999).The relationship between female and unemployment and fertility in Africa.Demography 18(4) 544-575.

DFID (2005).Gender equality and the millennium development goals.A discussion paper of the World Bank. Washington, DC.

Isiuigo-Abanihe, U.C. (1996). Determinants of fertility in Nigeria.Ibadan Sociology Series 3. International centre for research on women (2008)

Kabeer, N. (2001). Conflicts over credit: Re-evaluating the empowerment potential of loans to women inrural Bangladensh. World development.

Killby, P. (2002). Microfinance and poverty alleviation: The dangers of a development,.National centrefor development studies.Australian National University.

Krishna,O.(2003). Social capital community driven development and empowerment.A short note onconcepts and operations. World Bank working papers. 33077.

Lloyd, C.B. (1991). The contribution of the world fertility surveys to an understanding of the relationship between women's work and fertility. Studies in family planning 22(3) 144-61.

Malhotra.A. and Mark, M. (1997). Schooling and working. Empowering women in Developing countries

Mayoux, L. (2001). Summary: Women empowerment through sustainable microfinance: rethinking bestpractice: Gender and microfinance. University of British Columbia

Oladimeji, R.T. (1999). A social structural analysis of the effect of women's employment on fertility in urban Nigeria.Journal of Developing Societies 15(2) 172-88.

UNFPA (2006).Women's economic empowerment, meeting the needs of impoverished women.Workshop report, Unfpa, New York.

United Nations (2011). The Millenium development goals report (New York:Un)

United Nations (2012). Millenium development goals monitor accessed online athttp://www.mdgmonitor.org/goal.

Uyanga, J. (1996). Family size and the participation of women in labour force.A Nigeria casestudy.African Urban Notes 2.59-72. 